\title{
Physico-Chemical Properties of Bio-Oils from Pyrolysis of Lignocellulosic Biomass with High and Slow Heating Rate
}

\author{
Sonil Nanda ${ }^{1,2}$, Pravakar Mohanty ${ }^{3}$, Janusz A. Kozinski ${ }^{1} \&$ Ajay K. Dalai ${ }^{2}$ \\ ${ }^{1}$ Lassonde School of Engineering, York University, Ontario, Canada \\ ${ }^{2}$ Department of Chemical and Biological Engineering, University of Saskatchewan, Saskatchewan, Canada \\ ${ }^{3}$ Thermo-Chemical Conversion Division, Sardar Patel Renewable Energy Research Institute, Gujarat, India \\ Correspondence: Ajay K. Dalai, Department of Chemical and Biological Engineering, University of \\ Saskatchewan, Saskatoon, Saskatchewan, S7N 5A9, Canada. Tel: 1-306-966-4771. E-mail: ajay.dalai@usask.ca
}

Received: April 17, 2014 Accepted: June 10, 2014 Online Published: July 8, 2014

doi:10.5539/eer.v4n3p21 URL: http://dx.doi.org/10.5539/eer.v4n3p21

\begin{abstract}
Bio-oil is a major product of biomass pyrolysis that could potentially be used in motor engines, boilers, furnaces and turbines for heat and power. Upon catalytic upgrading, bio-oils can be used as transportation fuels due to enhancement of their fuel properties. In this study, bio-oils produced from lignocellulosic biomasses such as wheat straw, timothy grass and pinewood were estimated through slow and high heating rate pyrolysis at $450{ }^{\circ} \mathrm{C}$. The slow heating rate $\left(2{ }^{\circ} \mathrm{C} / \mathrm{min}\right)$ pyrolysis resulted in low bio-oil yields and high amount of biochars, whereas the high heating rate $\left(450^{\circ} \mathrm{C} / \mathrm{min}\right)$ pyrolysis produced significant amount of bio-oils with reduced biochar yields. The physico-chemical and compositional analyses of bio-oils were achieved through carbon-hydrogen-nitrogen-sulfur (CHNS) studies, calorific value, Fourier transform-infra red (FT-IR) spectroscopy, gas chromatography-mass spectrometry (GC-MS), electrospray ionization-mass spectrometry (ESI-MS) and nuclear magnetic resonance (NMR) spectroscopy. The yields of bio-oils produced from the three biomasses were 40-48 wt.\% through high heating rate pyrolysis and 18-24 wt.\% through slow heating rate pyrolysis. The chemical components identified in bio-oils were classified into five major groups such as organic acids, aldehydes, ketones, alcohols and phenols. The percent intensities of hydrogen and carbon containing species were calculated from ${ }^{1} \mathrm{H}$ and ${ }^{13} \mathrm{C}-\mathrm{NMR}$. The study on bio-oils from herbaceous and woody biomasses revealed their potentials for fossil fuel substitution and bio-chemical production.
\end{abstract}

Keywords: lignocellulosic biomass, pyrolysis, heating rate, bio-oil, compositional analysis

\section{Introduction}

Over the last few decades, interest in using biomass derived fuels has increased tremendously due to the concerns of global warming from anthropogenic emissions of greenhouse gases, climate change and reduction in fossil fuel reserves. In order to decrease the dependence on fossil fuels and reduce $\mathrm{CO}_{2}$ emissions there is an urgent need for energy conservation and use of renewable energy resources. A promising approach is to lower atmospheric $\mathrm{CO}_{2}$ while producing energy from bio-oil and biochar which are two major products of biomass pyrolysis (Brown, Wright, \& Brown, 2011). The worldwide petroleum consumption was recorded to 90 million barrels per day in 2012, however the consumption is expected for increase to 103 million barrels per day in 2025 (Mohanty et al., 2013). The increasing consumption and depleting supplies of fossil fuels are necessitating the development of new energy alternatives for possible substitution of fossil fuels.

Biomass utilization is one of the most cost-effective routes to carbon-neutral energy and is expected to be the source of immense practical value to produce renewable liquid fuels (He, Ye, English, \& Satrio, 2009). Lignocellulosic biomasses have tremendous potentials in production of fuels and chemicals. These materials are available in surplus worldwide and do not compete with the food supply (Sukumaran et al., 2010). The annual lignocellulosic biomass availability in USA and Canada ranges up to 256 and 1000 million dry tons, respectively (Gronowska, Joshi, \& MacLean, 2009). For the production of bio-oils, lignocellulosic biomasses are thermally degraded via pyrolysis at higher temperatures with varying heating rates (Czernik \& Bridgwater, 2004).

The slow heating rate (SHR) pyrolysis or slow pyrolysis typically operates at $400-500{ }^{\circ} \mathrm{C}$ with a low heating rate allowing the biomass to undergo endothermic degradation and release considerable amounts of biochar and 
pyrolysis gases (Nanda, Mohammad, Reddy, Kozinski, \& Dalai, 2014). In contrast, high heating rate (HHR) pyrolysis or fast pyrolysis typically occurs at temperatures $\geq 400{ }^{\circ} \mathrm{C}$ and has a heating rate $>300{ }^{\circ} \mathrm{C} / \mathrm{min}$. The HHR pyrolysis gasifies the biomass under reduced environment (absence of oxygen), producing small amount of biochar and significant amount of bio-oils that can be upgraded to transportation fuels (Mohanty, Pant, Naik, Das, \& Vasudevan, 2011). Along with the energy production from both pyrolysis scenarios, certain levels of valuable co-products are also generated such as meat browning and food flavoring agents, wood preservatives, adhesives and other useful chemical components (Czernik \& Bridgwater, 2004).

Compared to SHR pyrolysis that is usually operated in fixed-bed reactors for a longer residence time, HHR pyrolysis is mostly operated in fluidized-beds having short residence time. However, some recent studies on crop stems (Stals et al., 2010), wood (French \& Czernik, 2010) and coconut shells (Siengchum, Isenberg, \& Chuang, 2013) have demonstrated the use of fixed-bed batch reactors for HHR pyrolysis. Moreover, a typical HHR pyrolysis is performed with a short vapor residence time of 1-5 s, while some studies reveal residence times of $30-88 \mathrm{~s}$ in the pyrolysis of rise husk (Tsai, Lee, \& Chang, 2007) and cotton seed (Putun, 2010) in fixed-bed reactors. Based on these investigations, the current study employs a fixed-bed reactor for both SHR and HHR pyrolysis of lignocellulosic biomass from herbaceous (wheat straw, timothy grass) and forestry (pinewood) resources. With this objective, the pyro-oil, biochar and gas yields from SHR and HHR pyrolysis along with the compositional analysis of pyro-oils were evaluated.

\section{Materials and Methods}

\subsection{Biomass Samples}

Bio-oils were produced from the pyrolysis of three lignocellulosic biomasses obtained from Saskatchewan, Canada, namely wheat straw or WS (Triticum aestivum), timothy grass or TG (Phleum pratense) and pinewood or PW (Pinus banksiana) in a laboratory captive wire-mesh fixed-bed reactor. The physiochemical characteristics of the three biomasses have been described by Nanda et al. (2013). Around $5 \mathrm{~kg}$ of each biomass was collected for chopping, crushing and air-drying. Air-dried biomasses were pulverized in a Wiley mill with a sieve screen of $1.3 \mathrm{~mm}$. The pulverized samples were stocked in glass jars at room temperature prior to pyrolysis experiments. A sample size of $10 \mathrm{~g}$ biomass per batch experiment was used for both HHR and SHR pyrolysis. All experiments and analysis were performed in triplicates with a standard deviation less than $\pm 5 \%$.

\subsection{Thermogravimetric Analysis (TGA)}

The devolatilization characteristics of the biomasses were determined through TGA analysis in a PerkinElmer Pyris Diamond TG/DTA instrument (PerkinElmer, USA). $0.5 \mathrm{~g}$ of biomass sample was subjected to a temperature program of 25 to $600{ }^{\circ} \mathrm{C}$ at a heating rate of $10{ }^{\circ} \mathrm{C} / \mathrm{min}$. The purge gas was argon at a flow rate of 10 $\mathrm{mL} / \mathrm{min}$. The rate of weight loss with respect to temperature was recorded to determine the temperature for pyrolysis experiments.

\subsection{Slow and High Heating Rate Pyrolysis}

Both HHR and SHR pyrolysis of biomasses were performed in a wire-mesh fixed-bed inconel tubular reactor placed in an electrically heating ATS furnace under inert $\mathrm{N}_{2}$ atmosphere with a flow rate of $80 \mathrm{~mL} / \mathrm{min}$. For HHR pyrolysis, biomass sample $(10 \mathrm{~g})$ was heated to $450^{\circ} \mathrm{C}$ at a high heating rate of $450{ }^{\circ} \mathrm{C} / \mathrm{min}$ with a residence time of $30 \mathrm{~s}$ for each batch run. For SHR pyrolysis, same quantity $(10 \mathrm{~g})$ of biomass sample was heated to $450{ }^{\circ} \mathrm{C}$ at a slow heating rate of $2{ }^{\circ} \mathrm{C} / \mathrm{min}$ with a residence time of $30 \mathrm{~min}$. After the pyrolysis experiments, the yields of pyrolysis liquids and biochars were determined by weighing. The liquid products consisting of aqueous and oil phases were separated using a rotary evaporator and subsequently weighed. The slow pyrolysis bio-oils were denoted as SWSP (slow heating rate pyrolysis wheat straw pyro-oil), STGP (slow heating rate pyrolysis timothy grass pyro-oil) and SPWP (slow heating rate pyrolysis pinewood pyro-oil). Similarly, bio-oils from HHR pyrolysis were represented as HWSP (high heating rate pyrolysis wheat straw pyro-oil), HTGP (high heating rate pyrolysis timothy grass pyro-oil) and HPWP (high heating rate pyrolysis pinewood pyro-oil).

\subsection{Ultimate Analysis and Higher Heating Value (HHV)}

The carbon-hydrogen-nitrogen-sulfur (CHNS) analysis of bio-oils was performed using an Elementar CHNS analyzer. The HHV was calculated from the percent of carbon, hydrogen and oxygen from CHNS analysis using the modified Dulong's formula as mentioned below (Theegala \& Midgett, 2012).

$$
\mathrm{HHV}(\mathrm{MJ} / \mathrm{kg})=\frac{33.5 \times \mathrm{wt} . \% \mathrm{C}}{100}+\frac{142.3 \times \mathrm{wt} . \% \mathrm{H}}{100}-\frac{15.4 \times \mathrm{wt} . \% \mathrm{O}}{100}
$$




\subsection{Fourier Transform Infrared (FT-IR) Spectroscopy}

FT-IR analysis was carried out to characterize the organic functional groups in the bio-oil samples. Bio-oils obtained from three feedstocks were analyzed by making smears between two quartz plates in a PerkinElmer FT-IR system Spectrum GX (PerkinElmer, USA). Each spectrum was an average of 64 scans from 400-4000 $\mathrm{cm}^{-1}$ at $2 \mathrm{~cm}^{-1}$ spectral resolution. FT-IR data interpretations for each spectrum were based on literature survey using extensive elucidation.

\subsection{Gas Chromatography-Mass Spectrometry (GC-MS)}

The liquid products obtained from the pyrolysis of the three biomasses were analyzed through a PerkinElmer Clarus-600 GC-MS (PerkinElmer, USA) for identification and quantification of their chemical components. The quantitative analysis for pyro-oil components was conducted by comparing peak area of internal standard detected by FID. Fluoranthene (Sigma-Aldrich, Canada) was used as an internal standard ( $50 \mathrm{mg} / 2 \mathrm{~mL}$ acetone). $50 \mu \mathrm{L}$ of fluoranthene solution was added to each pyro-oil sample. The capillary column used was an Elite-5 MS $\left(30 \mathrm{~m} \times 0.25 \mathrm{~mm} \times 0.25 \mu \mathrm{m}\right.$, PerkinElmer, USA) and the injector temperature was maintained at $250{ }^{\circ} \mathrm{C}$. The oven temperature was programmed from 40 to $300{ }^{\circ} \mathrm{C}$ at a heating rate of $3{ }^{\circ} \mathrm{C} / \mathrm{min}$. Helium (chromatographic grade) was used as the carrier gas with a $1 \mathrm{~mL} / \mathrm{min}$ flow rate. The split ratio of injection was set at 1:20. The mass range $(\mathrm{m} / \mathrm{z})$ of the mass spectrometer was set from 15 to 900 . The compounds were identified using the National Institute of Standards and Technology (NIST) mass spectral library.

\subsection{Electrospray Ionization-Mass Spectrometry (ESI-MS) Analysis}

The bio-oil fractions were analyzed by ESI-MS in positive (+ve) and negative ( - ve) ion, and ammonium acetate dosing modes. Compounds such as $\mathrm{N}$-heterocyclics which can accept protons to produce molecular ions were analyzed in the $+\mathrm{ve}$ ion mode. On the other hand, compounds such as fatty acids that release protons to form negative molecular ions were determined in the -ve ion mode. All the spectra were recorded on a Micro mass Quattro-LC triple-quadrupole mass spectrometer fitted with Z-spray ion source and the data were analyzed by a MassLynx data acquisition and processing software. The compounds corresponding to the $\mathrm{m} / \mathrm{z}$ were identified by comparing their ESI-MS spectra with those of known compounds from the Wiley mass spectral library software.

Typically, $20 \mu \mathrm{L}$ of sample solution ( $1 \mathrm{mg}$ bio-oil per $5 \mathrm{~mL}$ HPLC grade methanol/acetonitrile) was introduced into the mass spectrometer with the mobile phase (1:1 v/v mixture of HPLC grade methanol and acetonitrile), running at a flow rate of $40 \mu \mathrm{L} / \mathrm{min}$. Nitrogen was used as the desolvation gas. The inlet capillary voltage was held between 4.0 and $4.5 \mathrm{keV}$ in +ve ion mode, whereas in -ve ion mode it was between 3.5 and $4.0 \mathrm{keV}$. ESI-MS spectra were obtained in the range of 20 to $500 \mathrm{~m} / \mathrm{z}$.

\subsection{Nuclear Magnetic Resonance (NMR) Analysis}

${ }^{1} \mathrm{H}-\mathrm{NMR}$ and ${ }^{13} \mathrm{C}$-NMR spectral analyses were performed for bio-oils obtained from pyrolysis of the three biomasses in a Bruker Advance $500 \mathrm{MHz}$ NMR spectrometer (Bruker BioSpin, Canada) equipped with a $5 \mathrm{~mm}$ inverse triple resonance TXI probe for ${ }^{1} \mathrm{H}$ and ${ }^{13} \mathrm{C}$ analysis. For sample preparation, bio-oils were filtered using $0.2 \mu \mathrm{m}$ non-pyrogenic sterilized filter discs (VWR, Canada) and dissolved in $99.9 \%$ of $\mathrm{CDCl}_{3}$ (Merck, Germany) at a concentration higher than $0.5 \mathrm{~g} / \mathrm{mL}$. All the acquired NMR spectra were processed through Topspin version 2.1 software with a Gaussian function. The chemical shifts in ${ }^{1} \mathrm{H}$ and ${ }^{13} \mathrm{C}-\mathrm{NMR}$ spectra were integrated to quantify various components based on their hydrogen and carbon bonding behavior.

\section{Results and Discussion}

\subsection{Thermogravimetric Analysis}

Thermogravimetric analysis of biomasses was carried out in order to determine the temperature range for slow and high heating rate pyrolysis. Figure 1 shows the devolatilization characteristics for wheat straw, timothy grass and pinewood. All the three biomasses started to devolatilize between 200 and $250^{\circ} \mathrm{C}$. A sudden weight loss in all biomasses was found at around $250-350{ }^{\circ} \mathrm{C}$. This is usually characterized by the loss of moisture, volatile compounds and organic components including cellulose, hemicellulose and lignin (Theegala \& Midgett, 2012). This phase was followed by a steady and slower weight loss phase that started at around $400{ }^{\circ} \mathrm{C}$ and continued up to $450{ }^{\circ} \mathrm{C}$, indicating biochar formation. Hence, the temperature for pyrolysis was selected at $450{ }^{\circ} \mathrm{C}$. Hemicellulose in biomass is known to degrade in the temperature range of $200-300{ }^{\circ} \mathrm{C}$, cellulose at $25-350{ }^{\circ} \mathrm{C}$ and lignin at a wider range of $200-500{ }^{\circ} \mathrm{C}$ (Carrier et al., 2011). 


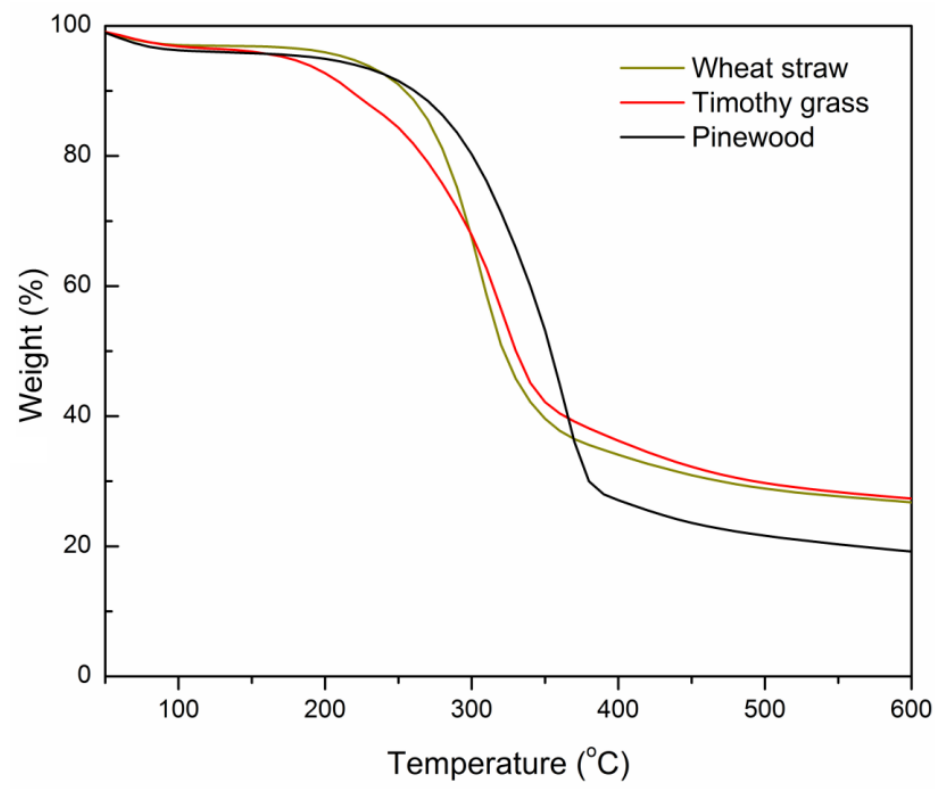

Figure 1. Thermogravimetric analysis of biomass samples

\subsection{Ultimate Analysis and Higher Heating Value}

The SHR pyrolysis of wheat straw, timothy grass and pinewood resulted in yields of 18-24 wt.\% bio-oils, 41-44 wt.\% biochars and 24-27 wt.\% gases (Figure 2). On the other hand, HHR pyrolysis resulted in 40-48 wt.\% bio-oils, 21-24 wt.\% biochars and 17-24 wt.\% gases from the three biomasses. Pinewood gave relatively high yield of bio-oils with lower gas yield compared to herbaceous biomasses. However, during each pyrolysis process the temperature, heating rate, heat flux, processing and residence times, gas conditions, feed density and particle size influence the yield of bio-oil and its chemical characteristics (Nanda, Mohammad, Reddy, Kozinski, \& Dalai, 2014).

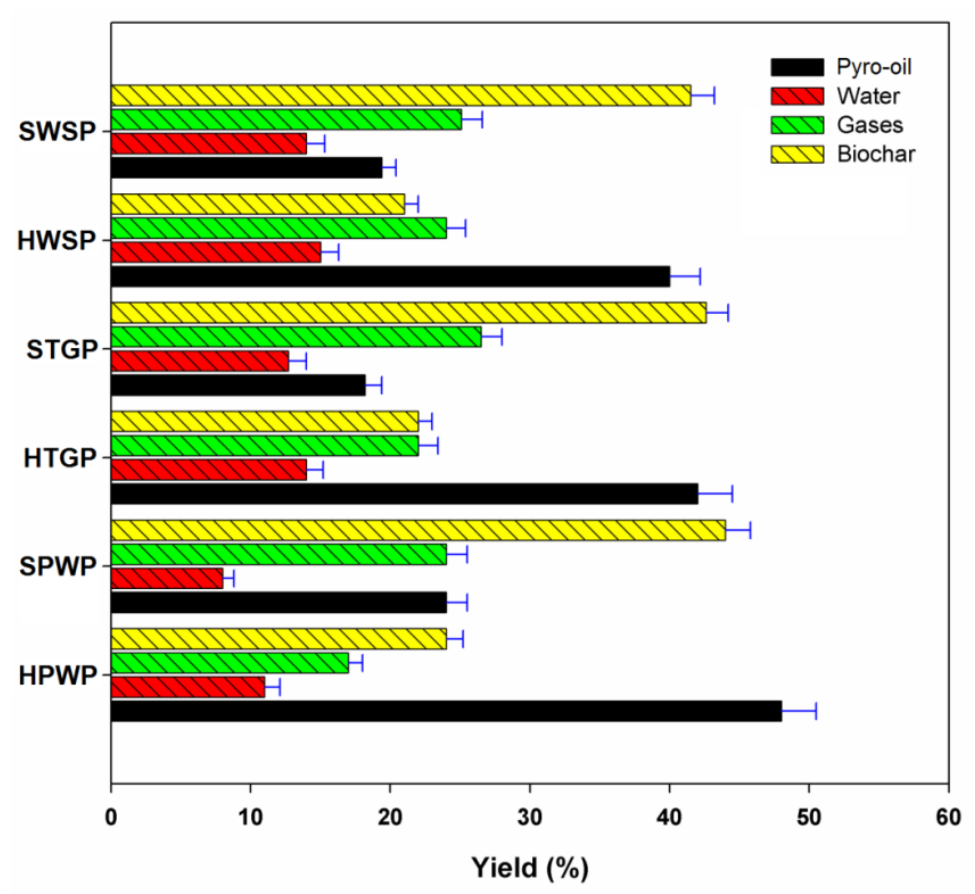

Figure 2. Yield of bio-oils, biochars and gases from HHR and SHR pyrolysis 
The residence time is considered as an important factor in determining the duration available for vapor phase and vapor-solid phase reactions to occur in the reactor. By increasing the heating rate from $2{ }^{\circ} \mathrm{C} / \mathrm{min}$ to $450{ }^{\circ} \mathrm{C} / \mathrm{min}$, the yield and composition of bio-oils changed drastically.

Table 1. Ultimate analysis and higher heating value of HHR and SHR bio-oils

\begin{tabular}{ccccccccccc}
\hline Bio-oils & \multicolumn{4}{c}{ Ultimate analysis (wt.\%) } & \multicolumn{3}{c}{ Atomic ratio } & \multirow{2}{*}{ HHV (MJ/kg) } \\
\cline { 2 - 8 } & $\mathrm{C}$ & $\mathrm{H}$ & $\mathrm{N}$ & $\mathrm{S}$ & $\mathrm{O}$ & $\mathrm{O} / \mathrm{C}$ & $\mathrm{H} / \mathrm{C}$ & $\mathrm{N} / \mathrm{C}$ & \\
\hline SWSP & 41.7 & 8.2 & 1.5 & 0.2 & 48.4 & 0.9 & 2.4 & 0.03 & 18.2 \\
HWSP & 52.3 & 9.4 & 1.9 & 0.6 & 35.8 & 0.5 & 2.2 & 0.03 & 25.4 \\
STGP & 44.9 & 8.4 & 1.8 & 0.5 & 44.4 & 0.7 & 2.2 & 0.03 & 20.2 \\
HTGP & 49.2 & 9.3 & 2.2 & 0.9 & 38.4 & 0.6 & 2.3 & 0.04 & 23.8 \\
SPWP & 46.5 & 9.1 & 1.4 & 0.01 & 43.0 & 0.7 & 2.3 & 0.03 & 21.9 \\
HPWP & 54.4 & 9.6 & 1.6 & 0.4 & 34.0 & 0.5 & 2.1 & 0.03 & 26.6 \\
\hline
\end{tabular}

Note: Oxygen (wt.\%) was calculated from the difference of C, H, N and S.

The CHNS analysis of HHR and SHR bio-oils from three biomasses are presented in Table 1. The carbon content was high in case of HHR bio-oils (49.2-54.4 wt.\%) than SHR bio-oils (41.7-46.5 wt.\%). In the same way, the average hydrogen content in HHR bio-oils was higher than that of SHR bio-oils. The higher carbon and hydrogen levels in HHR bio-oils signified a higher degree of cross-linking and occurrence of high molecular weight components compared to SHR bio-oils.

The atomic ratios $(\mathrm{H} / \mathrm{C}, \mathrm{O} / \mathrm{C}, \mathrm{N} / \mathrm{C}$ and $\mathrm{S} / \mathrm{C})$ for bio-oils were calculated to elucidate their empirical formulae. The empirical formula for HWSP, HTGP and HPWP were $\mathrm{CH}_{2.2} \mathrm{~N}_{0.03} \mathrm{O}_{0.5}, \mathrm{CH}_{2.3} \mathrm{~N}_{0.04} \mathrm{O}_{0.6}$ and $\mathrm{CH}_{2.1} \mathrm{~N}_{0.03} \mathrm{O}_{0.5}$, respectively. Similarly the empirical formula for SWSP, STGP and SPWP were $\mathrm{CH}_{2.4} \mathrm{~N}_{0.03} \mathrm{O}_{0.9}, \mathrm{CH}_{2.2} \mathrm{~N}_{0.03} \mathrm{O}_{0.7}$ and $\mathrm{CH}_{2.3} \mathrm{~N}_{0.03} \mathrm{O}_{0.7}$, respectively. The HHV of HHR bio-oils (23.6-26.6 MJ/kg) was comparatively higher than that of SHR bio-oils (18.2-21.9 MJ/kg). The higher HHV along with higher average values of carbon and hydrogen with low oxygen levels in HHR bio-oils suggested their better fuel properties than SHR bio-oils. Pinewood-derived bio-oils had relatively higher HHV than their corresponding SHR and HHR bio-oils due to highest levels of carbon $(46.5,54.4$ wt. \%) and hydrogen $(9.1,9.6$ wt.\%) content.

\subsection{Fourier Transform Infrared Spectroscopy}

The FT-IR spectra of bio-oil fractions from HHR and SHR pyrolysis of wheat straw, timothy grass and pinewood are presented in Figure 3. Various peaks with strong, medium, broad and weak intensities were found indicating different bond types such as $\mathrm{C}-\mathrm{H}, \mathrm{C}-\mathrm{O}, \mathrm{C}-\mathrm{O}, \mathrm{O}-\mathrm{H}, \mathrm{N}-\mathrm{H}$ and $\mathrm{C}-\mathrm{N}$ in the bio-oil fractions. The $\mathrm{C}-\mathrm{O}$ stretching vibrations between 1680 and $1780 \mathrm{~cm}^{-1}$ was because of ketones and aldehydes, whereas the O-H stretching vibrations between 3200 and $3450 \mathrm{~cm}^{-1}$ were from phenols and alcohols (Schnitzer, Monreal, Facey, \& Fransham, 2007). Similarly, the bands between 1575 and $1675 \mathrm{~cm}^{-1}$ represented $C-C$ stretching vibrations due to the presence of alkenes and aromatics. The bands at $3100 \mathrm{~cm}^{-1}$ indicated the presence of hydrocarbon groups bound to aromatic rings. The $\mathrm{C}-\mathrm{H}$ stretching vibrations between 2800 and $3000 \mathrm{~cm}^{-1}$ and deformation vibrations between 1350 and $1475 \mathrm{~cm}^{-1}$ indicated the presence of alkanes.

Presence of both $\mathrm{O}-\mathrm{H}$ and $\mathrm{C}-\mathrm{O}$ stretching vibrations indicated presence of carboxylic acids and their derivatives in the bio-oils. The main absorption bands corresponded to $3005 \mathrm{~cm}^{-1}$ assigned to $=\mathrm{C}-\mathrm{H}$ stretching of the $\mathrm{C}-\mathrm{C}$ double bonds. The 2963 and $2852 \mathrm{~cm}^{-1}$ region is assigned as stretching of $\mathrm{C}-\mathrm{H}$ saturated bonds, $1741 \mathrm{~cm}^{-1}$ as $\mathrm{C}=\mathrm{O}$ stretching of the carbonyl functionalities, $1585 \mathrm{~cm}^{-1}$ as $\mathrm{C}=\mathrm{C}$ stretching of the $\mathrm{C}-\mathrm{C}$ double bonds, $1168 \mathrm{~cm}^{-1}$ as $\mathrm{C}-\mathrm{O}-\mathrm{C}$ stretching of the ester functionalities and $723 \mathrm{~cm}^{-1}$ as $\mathrm{C}-\mathrm{H}$ plane stretching of saturated $\mathrm{C}-\mathrm{H}$ bonds (Siengchum, Isenberg, \& Chuang, 2013). In the region of 1800 and $900 \mathrm{~cm}^{-1}$, many absorption bands were associated with various components and those vibration modes were due to the derivatives of carbohydrates and lignin. In particular, the $\mathrm{C}=\mathrm{O}$ carbonyl components $\left(1733 \mathrm{~cm}^{-1}\right)$ as well as $\mathrm{C}-\mathrm{C}$ alkenes and aromatics $\left(1677 \mathrm{~cm}^{-1}\right)$ were found to be predominant in HHR bio-oils. On the other hand, C-H alkanes (2963 and $\left.2852 \mathrm{~cm}^{-1}\right)$ along with $\mathrm{C} \equiv \mathrm{C}$ alkynes $\left(2370 \mathrm{~cm}^{-1}\right)$ were distinctively found in prominent amounts in SHR bio-oils. 

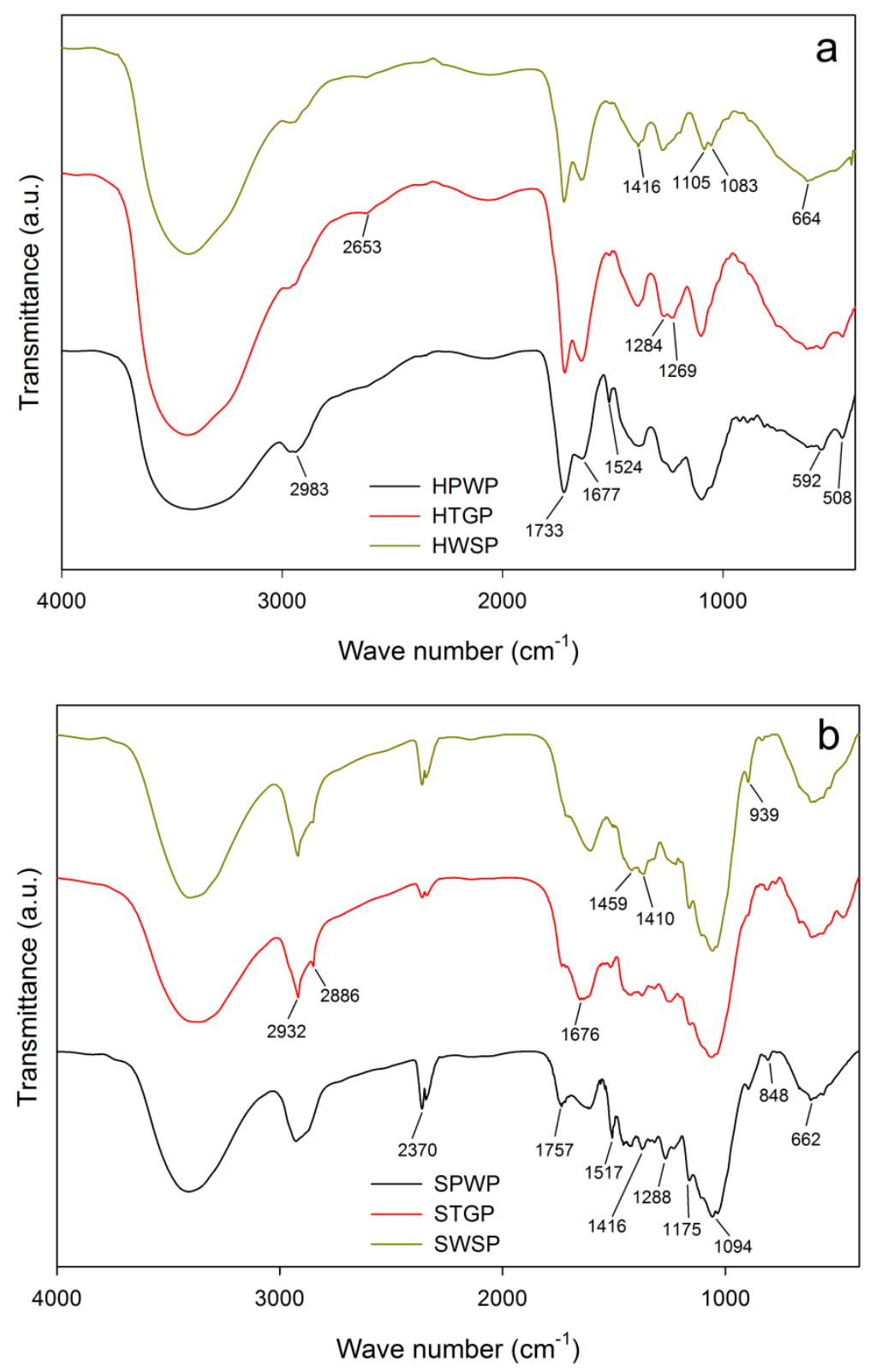

Figure 3. FT-IR spectral analysis for (a) HHR and (b) SHR bio-oils

\subsection{Gas Chromatography-Mass Spectrometry}

GC-MS analysis for the bio-oils was performed to study the diversity of components of SHR and HHR bio-oils. The peaks of the chromatogram were matched with NIST library to identify the compounds. Most of the compounds identified through in the bio-oils originated due to the thermal cracking of cellulose, hemicellulose and lignin in the biomass. Numerous amounts of compounds were identified in the bio-oils (Mahinpey, Murugan, Mani, \& Raina, 2009). Due to their diversity, they were categorized into five major classes, namely monoaromatics, polyaromatics, aliphatics, oxygenates and nitrogenates. The variation of occurrence of these organic compounds in the HHR and SHR bio-oils is shown in Figure 4. Oxygenated and nitrogenated compounds were prominent in SHR bio-oils, whereas aliphatics were relatively high in HHR bio-oils which increased their heating value (Table 1). 


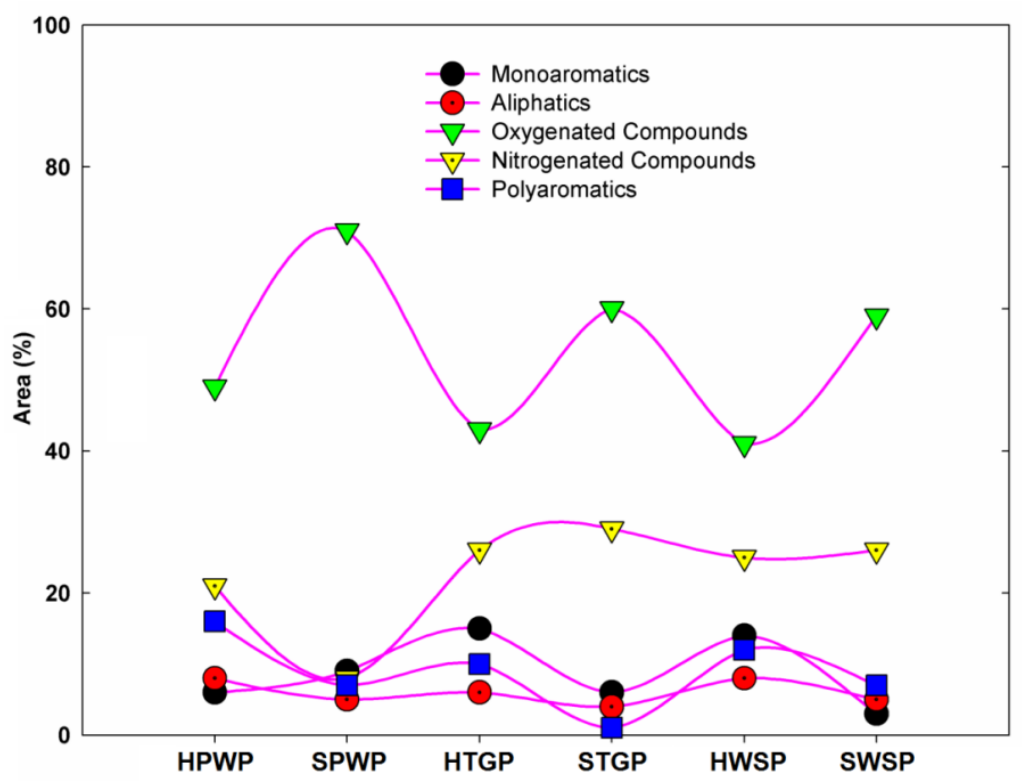

Figure 4. Distribution of components in HHR and SHR pyro-oils from GC-MS analysis

Components such as carboxylic acids, phenols, ketones, aldehydes, esters and amides were the chief chemical groups present in the bio-oils. This is in accordance to the findings of FT-IR spectral analysis. Pinewood-derived bio-oils contained significant amount of phenolic components. This was due to the higher amount of lignin content in pinewood compared to wheat straw and timothy grass (Nanda et al., 2013). Some of the derivatives from lignin found in the HHR and SHR bio-oils were 1,2-benzenediol; 4-methoxy phenol; 4-methylphenol; 2-methoxy-4-methylphenol; 2,4-dimethylphenol; 4-ethyl-2-methoxyphenol; 2-methoxy-4-vinylphenol; 2-methoxy-4-propylphenol; 2,6-dimethoxy-phenol; 3,4-dimethoxytoluene; 1,2,4-trimethoxybenzene; 1-(2-hydroxy-5-methylphenyl)-ethanone; 1-(4-hydroxy-3-methoxyphenyl)-ethanone; 2-methoxy-4-(1-propenyl)phenol; 1-(4-hydroxy-3-methoxyphenyl)-2-propanone and eugenol. Phenol was the most abundant phenolic compound present in HHR bio-oils, which was responsible in their higher carbon and hydrogen fractions. This also contributed to the higher heating value of HHR bio-oils compared to SHR bio-oils. The derivatives from cellulose and hemicellulose found in the bio-oils consisted of acetic acid; butyric acid; 3-methylbutyl ester-butanoic acid; 3-furancarboxylic acid; 2-methyl-furan; tetrahydro-2,5-dimethoxy-furan; tetrahydro-2furanmethanol; 3-bromopentane; dehydromevalonic lactone; 4-hydroxylbenzenesulfonic acid; methyl-(2hydroxy-3-ethoxy-benzyl)ether; 3,7,11,15-tetramethyl-2-hexadecane-1-ol (Acikalin, Karaca, \& Bolat, 2012).

\subsection{Electrospray Ionization-Mass Spectrometry Analysis}

Although GC-MS is an essential tool for studying the structures and molecular mass distributions of complex mixtures, it lags behind in measuring the molecular mass of the compound with intensity. However, ESI-MS is a useful tool for this purpose because it can successfully resolve high molecular mass and/or highly polar components that are generally not eluted through GC-MS. ESI-MS mass spectra in +ve, $-\mathrm{ve}$ and ammonium acetate modes for HHR bio-oils is given in Figure 5.

The maximum intensity was at about 157, 96 and $109 \mathrm{~m} / \mathrm{z}$ for HWSP, HTGP and HPWP, respectively. This suggests that HWSP comprised of components with molecular mass (amu) varying from 22-247 in +ve ion mode, 34-181 in -ve ion mode and 34-181 in -ve ion mode with ammonium acetate. Similarly, the ranges for HTGP varied from 71-272 in +ve ion mode, 34-191 in -ve ion mode and 44-181 in -ve ion mode with ammonium acetate. For HPWP, the ranges were 85-257 in +ve ion mode, 75-197 in -ve ion mode and 45-181 in -ve ion mode with ammonium acetate. ESI-MS and GC-MS results indicate that high molecular mass $(\geq 250 \mathrm{amu})$ components were due to the oligomeric species which originated mostly from lignin, whereas other remaining molecules were derived from cellulose and hemicelluloses (Demiral, Eryazici, \& Sensoz, 2012). These oligomers in bio-oils are responsible to having polymeric (repeat) units of carbon and hydrogen and increasing the heating value as a characteristic feature of HHR bio-oils (Table 1). However, the oxygenated compounds in the bio-oils have a tendency to undergo polymerization reactions during storage leading to formation of chemicals with high molecular masses. 

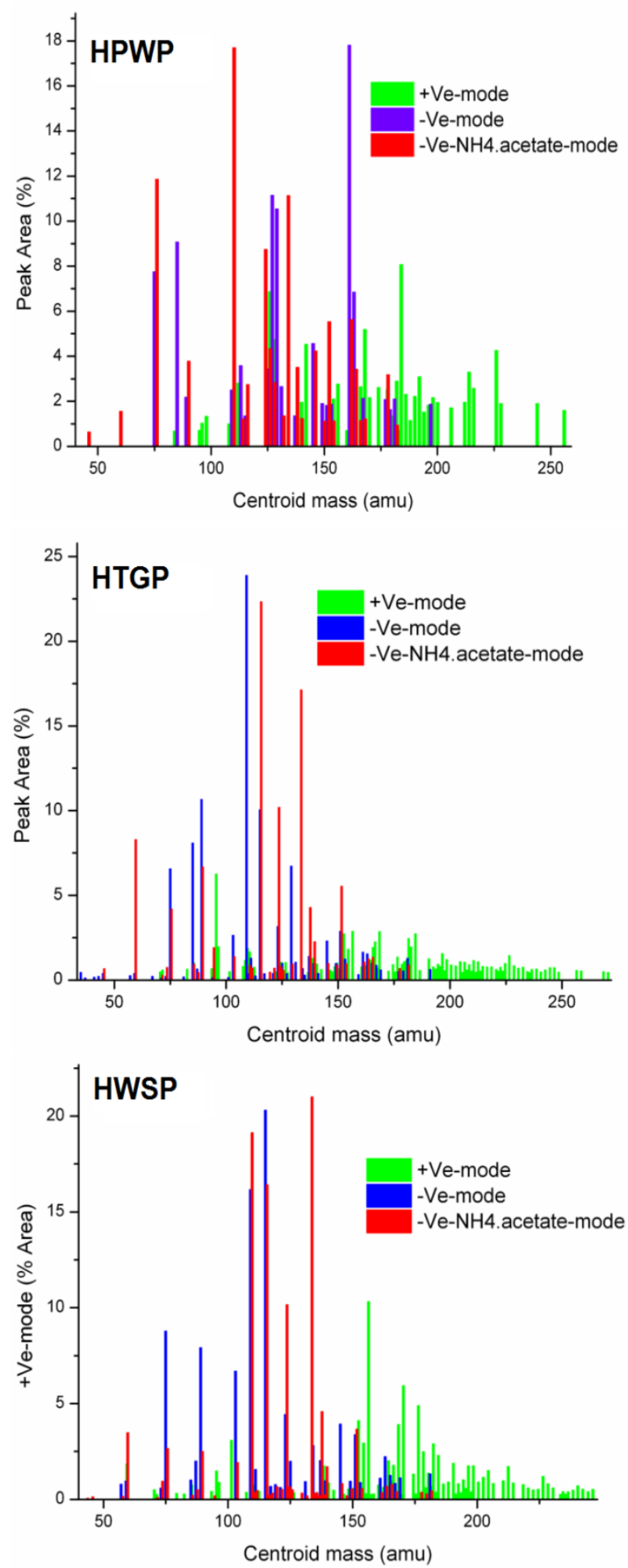

Figure 5. Distribution for centroid mass (amu) in HHR bio-oils through ESI-MS

\subsection{Nuclear Magnetic Resonance Analysis}

${ }^{1} \mathrm{H}-\mathrm{NMR}$ spectral assignments of HHR bio-oils is summarized in Tables 2. Long chain $-\mathrm{CH},-\mathrm{CH}_{3 \alpha}$ to aromatic ring and fewer formations of di-aromatic, tri and tetra-aromatic ring were observed. The bio-oils contained aromatics; phenolics or olefinics; ring join methylene; $\mathrm{CH}_{2}$ and $\mathrm{CH}_{\beta}$ to an aromatic ring; $\mathrm{CH}_{3}, \mathrm{CH}_{2}$ and $\mathrm{CH}_{\alpha}$ to an aromatic ring; $\beta-\mathrm{CH}_{3}, \mathrm{CH}_{2}$ and $\mathrm{CH}_{\gamma}$ or further to an aromatic ring; and $\mathrm{CH}_{3 \gamma}$ or further to an aromatic ring. Three major groups of chemicals were identified in bio-oils based on the proton type as aromatics, olefinics and 
aliphatics and were thus integrated. Aliphatic protons listed in Table 2 include methylene groups; $\mathrm{CH}_{3}, \mathrm{CH}_{2}$ and $\mathrm{CH}_{\alpha}$ to an aromatic ring; $\mathrm{CH}_{2}$ and $\mathrm{CH}_{\beta}$ to an aromatic ring; $\beta-\mathrm{CH}_{3}, \mathrm{CH}_{2}$ and $\mathrm{CH}_{\gamma}$ or further from an aromatic ring and $\mathrm{CH}_{3 \gamma}$ (Schnitzer, Monreal, Facey, \& Fransham, 2007). Based on the sequence of occurrence, HHR bio-oils contained aliphatics $(52-64 \%)$, olefinics $(21-35 \%)$ and aromatics $(<10 \%)$. In contrast, SHR bio-oils contained higher amount of aliphatics (46-57\%) followed by olefinics (29-31\%) and aromatics (15-25\%). The aliphatics and olifinics were relatively higher in HHR bio-oils due to their higher amount of carbon and hydrogen levels and lignin-derived components compared to SHR bio-oils. This is an indication of better fuel properties for HHR bio-oils.

Table 2. ${ }^{1}$ H-NMR spectral assignments for HHR bio-oils

\begin{tabular}{ll}
\hline $\begin{array}{l}\text { Chemical shifts } \\
\text { (ppm) }\end{array}$ & Assignments \\
\hline $\mathbf{0 . 5}-\mathbf{1 . 0}$ & $\mathrm{CH}_{3 \gamma}$ and further naphthenic- $\mathrm{CH}$ and $\mathrm{CH}_{2}$ \\
$\mathbf{1 . 0}-\mathbf{1 . 7}$ & $\mathrm{CH}_{2 \beta}$ and further. Some $\beta-\mathrm{CH}$ with $\mathrm{C}-\mathrm{C}-\mathrm{H}, \mathrm{Ar}-\mathrm{C}-\mathrm{H}, \mathrm{C}-\mathrm{CCH}_{3}, \mathrm{H}-\mathrm{C}-\mathrm{COOR}, \mathrm{H}-\mathrm{C}-\mathrm{COOH}$, \\
& $\mathrm{H}-\mathrm{C}-\mathrm{C}=\mathrm{O}, \mathrm{CH}_{2}, \mathrm{CH}_{\gamma}$, methyl and methylene groups, and for normal, branched alkanes \\
$\mathbf{1 . 7}-\mathbf{1 . 9}$ & Most $\mathrm{CH}, \mathrm{CH}_{2}, \beta$-hydro-aromatic \\
$\mathbf{2 . 1}-\mathbf{3 . 5}$ & $\mathrm{CH}, \mathrm{CH}_{2}, \mathrm{CH}_{3 \alpha}$ to an aromatic ring \\
$\mathbf{3 . 5}-\mathbf{4 . 5}$ & $\mathrm{CH}_{2}$ bridge (diphenylmethane) \\
$\mathbf{4 . 5}-\mathbf{6 . 0}$ & Olefinic hydrogen \\
$\mathbf{6 . 0}-\mathbf{7 . 2}$ & Single ring aromatic hydrogen \\
$\mathbf{7 . 2}-\mathbf{8 . 3}$ & Diaromatic and most of tri and tetra-aromatics \\
$\mathbf{8 . 3 - 8 . 9}$ & Some tri and tetra-aromatic rings \\
$\mathbf{8 . 9}-\mathbf{9 . 3}$ & Some tetra-aromatic rings \\
\hline
\end{tabular}

Note: The chemical shifts are calculated with reference to TMS (tetramethylsilane) at $0 \mathrm{ppm}$.

${ }^{13} \mathrm{C}$-NMR spectral assignments are given in Table 3. Although Table 3 shows a diverse spectral classification for ${ }^{13} \mathrm{C}-\mathrm{NMR}$, three major categories were carbonyls $(11.1-26.1 \%)$, aromatics $(30.3-35.8 \%)$, carbohydrates $(<7.5 \%)$, methoxy or hydroxy carbon (4.3-15.1\%) and alkyl carbons (27.4-38.4\%). The carbon-groups in HHR bio-oils ranged in the sequence: aromatics $(28-34 \%) \geq$ alkyl carbon $(25-30 \%)>$ carbonyl carbon $(10-23 \%)>$ methoxy or hydroxyl carbon $(5-18 \%)>$ carbohydrates $(<5 \%)$. However, SHR bio-oils had their ${ }^{13}$ C-NMR diversity as aromatics $(33-39 \%) \geq$ alkyl carbon $(21-24)>$ carbonyl carbon $(15-29 \%)>$ methoxy or hydroxyl carbon $(9-21 \%)>$ carbohydrates $(<15 \%)$. The concentration of carbohydrates in HHR bio-oils were lower compared to SHR bio-oils due to high heating rates $\left(450^{\circ} \mathrm{C} / \mathrm{min}\right)$ and short residence time $(30 \mathrm{~s})$. SHR bio-oils had relatively higher levels of aromatics, carbonyls, methoxy and hydroxyl carbon, and carbohydrates which result from the slower cracking of cellulose and hemicellulose in biomass due to slow heating rate $\left(2{ }^{\circ} \mathrm{C} / \mathrm{min}\right)$ and longer residence time (30 min). The higher amount of aromatics in SHR bio-oils is in accordance with the ${ }^{1} \mathrm{H}-\mathrm{NMR}$ results. 
Table $3 .{ }^{13} \mathrm{C}$-NMR spectral assignments for HHR bio-oils

\begin{tabular}{|c|c|}
\hline $\begin{array}{l}\text { Chemical } \\
\text { shifts (ppm) }\end{array}$ & Assignments \\
\hline $11-12.5$ & $\mathrm{CH}_{3 \gamma}$ or further from aromatic ring \\
\hline $12.5-15$ & $\mathrm{CH}_{3 \gamma}$ or further from aromatic ring. $\mathrm{CH}_{3}$ shielded by two adjacent rings and alkanes \\
\hline $15-18$ & $\mathrm{CH}_{3 \beta}$ in ethyl \\
\hline $18.0-20.5$ & $\mathrm{CH}_{3 \alpha}$ shielded by one adjacent ring or group. Some $\mathrm{CH}_{3 \alpha}$ hydroaromatic and naphthenic $\mathrm{CH}_{2}$ \\
\hline $20.5-22.5$ & $\begin{array}{l}\mathrm{CH}_{3} \text { not shielded by adjacent rings or groups. Some } \mathrm{CH}_{3 \alpha} \text { hydroaromatic, naphthenic } \mathrm{CH}_{2} \text { and } \\
\text { branched alkanes of the isoprenoid compounds }\end{array}$ \\
\hline $22.5-24$ & $\begin{array}{l}\mathrm{CH}_{2 \gamma} \text { and further adjacent to } \mathrm{CH}_{3} \text { terminal. } \mathrm{CH}_{2 \beta} \text { in non-substituted tetralin structures. Some } \\
\mathrm{CH}_{3 \alpha} \text { hydroaromatic and naphthenic } \mathrm{CH}_{2}\end{array}$ \\
\hline $24-27.5$ & Some $\mathrm{CH}_{2}$ naphthenic. $\mathrm{CH}_{\alpha}$ not shielded. $\mathrm{CH}_{2 \beta}$ in propyl and indane groups. $\mathrm{CH}_{3 \beta}$ in isopropyls \\
\hline $27.5-37$ & $\begin{array}{l}\mathrm{CH}_{2} \text { not adjacent to } \mathrm{CH} \text { in alkyl groups. } \mathrm{CH}_{2} \text { adjacent to alkyl } \mathrm{CH} \text { in some } \mathrm{CH}_{2 \alpha} \text { and } \mathrm{CH}_{2} \\
\text { adjacent to } \mathrm{CH}_{3} \text { terminal in alkyl substituents with more than four carbons. } \mathrm{CH}_{2} \text { in ring joining } \\
\text { ethylene groups. Some } \mathrm{CH}_{2} \text { naphthenics }\end{array}$ \\
\hline $37-60$ & $\mathrm{CH}$ alkyl groups (except isoalkyl). Naphthenic $\mathrm{CH}$. $\mathrm{CH}_{2}$ alkyl groups adjacent to $\mathrm{CH}$ \\
\hline $60-95$ & Alcohols, ethers, phenolic methoxys, carbohydrate sugars \\
\hline $95-110$ & Dioxy-alkyl-carbon \\
\hline 108 - 118 & Olefinics \\
\hline $118-129.5$ & Protonated aromatics. Some internal (quaternary) aromatics \\
\hline $129.5-135$ & Most internal aromatics \\
\hline 135 - 138 & Naphthenic substituted aromatics \\
\hline $138-160$ & Alkyl (other than methyl) substituted aromatics \\
\hline $165-175$ & Ester or amide carboxyls \\
\hline $170-182$ & Acid carboxyls \\
\hline $182-192$ & Quinone carboxyls \\
\hline $195-205$ & Aldehyde carbonyls \\
\hline $202-220$ & Ketone carbonyls \\
\hline
\end{tabular}

Note: The chemical shifts are calculated with reference to TMS (tetramethylsilane) at $0 \mathrm{ppm}$.

\section{Conclusions}

The bio-oil yields from wheat straw, timothy grass and pinewood were high in HHR pyrolysis (40-48 wt.\%) than SHR pyrolysis (18-24 wt.\%). The bio-oil yield, properties and composition changed with increasing the heating rate from $2{ }^{\circ} \mathrm{C} / \mathrm{min}$ to $450{ }^{\circ} \mathrm{C} / \mathrm{min}$. The functional groups of $\mathrm{C}-\mathrm{H}, \mathrm{C}-\mathrm{O}, \mathrm{O}-\mathrm{H}, \mathrm{N}-\mathrm{H}$ and $\mathrm{C}-\mathrm{N}$ were intense in HHR bio-oils because of higher degree of cross-linking. This resulted in high molecular weight components e.g., aliphatic, aromatics, phenolics, carboxylic acids and other cellulose, hemicellulose and lignin derivatives in the HHR bio-oils. HHR bio-oils contained long chain $-\mathrm{CH},-\mathrm{CH}_{3 \alpha}$ to aromatic rings with fewer di-aromatics, tri and tetra-aromatic rings. The concentration of carbohydrates were lower in HHR bio-oils due to rapid thermal cracking of biomass components, whereas the slow heating rate and longer residence time of SHR pyrolysis resulted in substantial amount of aromatics, carbonyls, methoxy and hydroxyl carbon, and carbohydrates in the resulting bio-oils. The high heating rate with high carbon and hydrogen content of HHR bio-oils suggested superior fuel properties compared to SHR bio-oils.

\section{Acknowledgments}

We acknowledge the Lassonde School of Engineering at York University and Saskatchewan Structural Sciences Centre at University of Saskatchewan for the research facilities. We also thank Natural Sciences and Engineering Research Council of Canada (NSERC) and Canada Research Chair (CRC) program for the financial support towards this research work. 


\section{References}

Acikalin, K., Karaca, F., \& Bolat, E. (2012). Pyrolysis of pistachio shell: Effects of pyrolysis conditions and analysis of products. Fuel, 95, 169-177. http://dx.doi.org/10.1016/j.fuel.2011.09.037

Brown, T. R., Wright, M. M., \& Brown, R. C. (2011). Estimating profitability of two biochar production scenarios: Slow pyrolysis vs fast pyrolysis. Biofuels, Bioproducts and Biorefining, 5, 54-68. http://dx.doi.org/10.1002/bbb.254

Carrier, M., Loppinet-Serani, A., Denux, D., Lasnier, J. M., Ham-Pichavant, F., Cansell, F., \& Aymonier, C. (2011). Thermogravimetric analysis as a new method to determine the lignocellulosic composition of biomass. Biomass and Bioenergy, 35, 298-307. http://dx.doi.org/10.1016/j.biombioe.2010.08.067

Czernik, S., \& Bridgwater, A. V. (2004). Overview of applications of biomass fast pyrolysis oil. Energy and Fuels, 18, 590-598. http://dx.doi.org/10.1021/ef034067u

Demiral, I., Eryazici, A., \& Sensoz, S. (2012). Bio-oil production from pyrolysis of corncob (Zea mays L.). Biomass and Bioenergy, 35, 43-49. http://dx.doi.org/10.1016/j.biombioe.2011.10.045

French, R., \& Czernik, S. (2010). Catalytic pyrolysis of biomass for biofuels production. Fuel Processing Technology, 91, 25-32. http://dx.doi.org/10.1016/j.fuproc.2009.08.011

Gronowska, M., Joshi, S., \& MacLean, H. L. (2009). A review of U.S. and Canadian biomass supply studies. Bioresources, 4, 341-369.

He, R., Ye, X. P., English, B. C., \& Satrio, J. A. (2009). Influence of pyrolysis condition on switchgrass bio-oil yield and physicochemical properties. Bioresource Technology, 100, 5305-5311. http://dx.doi.org/10.1016/j.biortech.2009.02.069

Mahinpey, N., Murugan, P., Mani, T., \& Raina, R. (2009). Analysis of bio-oil, biogas, and biochar from pressurized pyrolysis of wheat straw using a tubular reactor. Energy and Fuels, 23, $2736-2742$. http://dx.doi.org/10.1021/ef8010959

Mohanty, P., Nanda, S., Pant, K. K., Naik, S., Kozinski, J. A., \& Dalai, A. K. (2013). Evaluation of the physiochemical development of biochars obtained from pyrolysis of wheat straw, timothy grass and pinewood: effects of heating rate. Journal of Analytical and Applied Pyrolysis, 104, 485-493. http://dx.doi.org/10.1016/j.jaap.2013.05.022

Mohanty, P., Pant, K. K., Naik, S. N., Das, L. M., \& Vasudevan, P. (2011). Fuel production from biomass: Indian perspective for pyrolysis oil. Journal of Scientific and Industrial Research, 70, 668-674.

Nanda, S., Mohammad, J., Reddy, S. N., Kozinski, J. A., \& Dalai, A. K. (2014). Pathways of lignocellulosic biomass conversion to renewable fuels. Biomass Conversion and Biorefinery, 4, 157-191. http://dx.doi.org/10.1007/s13399-013-0097-z

Nanda, S., Mohanty, P., Pant, K. K., Naik, S., Kozinski, J. A., \& Dalai, A. K. (2013). Characterization of North American lignocellulosic biomass and biochars in terms of their candidacy for alternate renewable fuels. Bioenergy Research, 6, 663-677. http://dx.doi.org/10.1007/s12155-012-9281-4

Putun, E. (2010). Catalytic pyrolysis of biomass: effects of pyrolysis temperature, sweeping gas flow rate and MgO catalyst. Energy, 35, 2761-2766. http://dx.doi.org/10.1016/j.energy.2010.02.024

Schnitzer, M. I., Monreal, C. M., Facey, G. A., \& Fransham, P. B. (2007). The conversion of chicken manure to biooil by fast pyrolysis I. Analysis of biooils by FTIR and NMR spectroscopy. Journal of Environmental Science and Health, Part B: Pesticides, Food Contaminants, and Agricultural Wastes, 42, 71-77. http://dx.doi.org/10.1080/03601230601020894

Siengchum, T., Isenberg, M., \& Chuang, S. S. C. (2013). Fast pyrolysis of coconut biomass - An FTIR study. Fuel, 105, 559-565. http://dx.doi.org/10.1016/j.fuel.2012.09.039

Stals, M., Thijssen, E., Vangronsveld, J., Carleer, R., Schreurs, S., \& Yperman, J. (2010). Flash pyrolysis of heavy metal contaminated biomass from phytoremediation: Influence of temperature, entrained flow and wood/leaves blended pyrolysis on the behaviour of heavy metals. Journal of Analytical and Applied Pyrolysis, 87, 1-7. http://dx.doi.org/10.1016/j.jaap.2009.09.003

Sukumaran, R. K., Surender, V. J., Sindhu, R., Binod, P., Janu, K. U., Sajna, K. V., ... Pandey, A. (2010). Lignocellulosic ethanol in India: Prospects, challenges and feedstock availability. Bioresource Technology, 101, 4826-4833. http://dx.doi.org/10.1016/j.biortech.2009.11.049 
Tsai, W. T., Lee, M. K., \& Chang, Y. M. (2007). Fast pyrolysis of rice husk: Product yields and compositions. Bioresource Technology, 98, 22-28. http://dx.doi.org/10.1016/j.biortech.2005.12.005

Theegala, C. S., \& Midgett, J. S. (2012). Hydrothermal liquefaction of separated dairy manure for production of bio-oils with simultaneous waste treatment. Bioresource Technology, 107, 456-463. http://dx.doi.org/10.1016/j.biortech.2011.12.061

\section{Copyrights}

Copyright for this article is retained by the author(s), with first publication rights granted to the journal.

This is an open-access article distributed under the terms and conditions of the Creative Commons Attribution license (http://creativecommons.org/licenses/by/3.0/). 